\title{
A luta decolonial de professores militantes da causa negra em contextos de colonialidade germânica ${ }^{1}$
}

\author{
Militant teachers in a decolonial struggle for the black in Germanic coloniality contexts
}

\begin{abstract}
La lucha descolonial de profesores militantes de la causa negra en contextos de colonialidad germánica
\end{abstract}

Benício Backes - Universidade Feevale | Curso de Pedagogia | Novo Hamburgo | RS | Brasil. E-mail: beniciobackes@gmail.com

José Licínio Backes - Universidade Católica Dom Bosco - UCDB | Professor do PPGE/UCDB e PPGPSI/UCDB | Campo Grande | MS | Brasil. E-mail: backes@ucdb.br @ Đorci

Resumo: Neste artigo, baseado na análise de falas de professoras e professores negros de escolas públicas municipais da cidade de Novo Hamburgo/RS, militantes da causa negra, mostra-se a potência do seu movimento/fazer pedagógico quanto à produção de tensionamentos em relação a pretensas bases epistemológicas universalistas e, ao mesmo tempo, de construção de possibilidades de práticas educativas multi/interculturais críticas. A produção de dados foi feita mediante a prática de entrevista interativa e as análises foram tecidas como articulação dos campos teórico-metodológicos dos estudos étnico-raciais e dos estudos do grupo modernidade/colonialidade. Concluiu-se que, embora já haja conquistas, em diferentes frentes - espaços de participação e de reconhecimento, garantindo maior visibilidade à negritude em Novo Hamburgo - torna-se importante manter as apostas em atividades decoloniais mais continuadas.

Palavras-chave: Professores negros. Docência/militância. Colonialidade.

Abstract: In this paper, based on the analysis of speeches by black teachers from public schools in the city of Novo Hamburgo (RS) that are militants dedicated to the cause of the black people, we have shown the potency of their pedagogical movement/action regarding the problematization of pretentious universalist epistemological bases and, at the same time, the construction of possibilities of critical multi/intercultural educational practices. Data were collected by means of interactive interview, and the analyses were performed as an articulation of the methodological-theoretical fields of ethnical-racial studies and studies of the modernity/coloniality group. We have concluded that, despite the achievements seen in different settings - positions of participation and acknowledgement, which guarantee more visibility to blackness in Novo Hamburgo - it is important to keep on betting on continuing decolonial activities.

\footnotetext{
${ }^{1}$ A pesquisa teve apoio financeiro do PROSUC/CAPES. Trata-se de versão ampliada e aprofundada de trabalho apresentado no $8^{\circ}$ Seminário Brasileiro de Estudos Culturais e Educação e $5^{\circ}$ Seminário Internacional de Estudos Culturais e Educação, evento realizado pelo PPGE-ULBRA/RS em parceria com o PPGE - UFRGS, em Canoas, nos dias 25 a 27 de junho, de 2019.
}

- Recebido em 29 de setembro de 2019 • Aprovado em 05 de novembro de 2019 • e-ISSN: 2177-5796

DOI: http://dx.doi.org/10.22483/2177-5796.2019v21n3p965-989

Copyright @ 2019. Conteúdo de acesso aberto, distribuído sob os termos da Licença Internaonal da CreativeCommons - CC BY-NC-SA Atribuição Não Comercial (https://br.creativecommons.org/licencas/) - Permite distribuição e reprodução, desde que atribuam os devido créditos à publicação, ao autor(es) e que licenciem as novas criações sob termos idênticos. 
BACKES, Benício; BACKES, José Licínio. A luta decolonial de professores militantes da causa negra em contextos de colonialidade germânica.

Keywords: Black teachers. Teachers/ militancy. Coloniality.

Resumen: En el artículo, basado en el análisis de declaraciones de profesores y profesoras negros de escuelas públicas municipales de la ciudad de Novo Hamburgo/RS, militantes de la causa negra, se muestra la potencia de su movimiento /hacer pedagógico en lo que se refiere a la producción de tensionamientos con relación a las supuestas bases epistemológicas universalistas y, al mismo tiempo, de construcción de posibilidades de prácticas educativas multi/interculturales críticas. La producción de datos fue realizada mediante la práctica de entrevista interactiva y los análisis fueron tejidos como articulación de los campos teórico-metodológicos de los estudios étnico-raciales y de los estudios del grupo modernidad/colonialidad. Se concluyó que, por más que haya conquistas, en diferentes frentes - espacios de participación y de reconocimiento, garantizando mayor visibilidad a la negritud en Novo Hamburgo - se vuelve importante mantener las apuestas en actividades descoloniales más continuas.

Palabras clave: Profesores negros. Enseñanza/militancia. Colonialidad. 
BACKES, Benício; BACKES, José Licínio. A luta decolonial de professores militantes da causa negra em contextos de colonialidade germânica.

\section{Introdução}

Os descendentes de alemães que vieram ao Brasil, e no caso de nossa pesquisa, mais especificamente a Novo Hamburgo, foram incentivados pelo Estado Brasileiro que queria branquear o Brasil, ter um conjunto de trabalhadores europeus e livres, ou ainda, formar um exército de soldados europeus para defender a independência do Brasil recém-proclamada. Por outro lado, a Alemanha passava por uma situação de pobreza e forme no século XIX, o que fez com que muitos alemães, sobretudo, da região mais pobre, a região de Hunsrück, vissem o Brasil como uma oportunidade de escapar da pobreza e da fome (SPINASSÉ, 2008).

Mas, apesar de reconhecer a importância desse processo, a intenção do artigo é privilegiar o ponto de vista dos sujeitos negros que, antes mesmo da colonização alemã, já viviam na região de Novo Hamburgo, mas na condição de escravizados. Esse processo produziu um conjunto de características negativas e estereótipos em relação aos sujeitos negros que se mantém até hoje por meio da colonialidade.

Mas essa colonialidade sempre foi questionada pelos movimentos negros. Nesse contexto, de luta decolonial, impossível não trazer a Lei Nacional 10.639/2003 (BRASIL, 2003), pois ela impulsionou práticas decoloniais em várias escolas, geralmente protagonizadas por professores negros.

Nesse sentido, problematiza-se, inicialmente, a colonialidade germânica sob a ótica dos/das militantes que fizeram parte da pesquisa, uma militância negra que entende a colonialidade germânica como construção cultural, forjada pela branquidade como presença ausente (APPLE, 2001) e passível de desconstrução. Após, tecem-se algumas considerações sobre a potência do seu movimento/fazer pedagógico que, ao mesmo tempo em que tenciona as bases epistemológicas com pretensões de universalidade, produzidas pela modernidade/colonialidade, encontra-se engajado na construção de práticas educativas multi/interculturais críticas.

Em outras palavras, na caracterização e análise da colonialidade germânica de acordo com o olhar de militantes da causa negra, encontra-se a possibilidade de se entender como essa colonialidade é questionada/colocada em xeque pela implementação da Lei Nacional 10.639/2003 (BRASIL, 2003), nas escolas municipais de Novo Hamburgo/RS, uma lei decolonial que tende ao reconhecimento e à afirmação da História e da Cultura Afro-Brasileira e 
BACKES, Benício; BACKES, José Licínio. A luta decolonial de professores militantes da causa negra em contextos de colonialidade germânica.

é voltada à desconstrução de estereótipos e de práticas racistas. Assim, na análise/discussão que segue, junto às marcas da colonialidade germânica em Novo Hamburgo, embora a colonialidade germânica insista em se manter hegemônica, vislumbra-se o tensionamento desse lugar colonial hegemonizado mediante processos de relativização da verdade a partir da sua compreensão como produção cultural e visibilização/afirmação de diferentes lugares de enunciação, diferentes formas de contar a história, diferentes epistemologias e diferentes construções identitárias.

Pensar nas potencialidades da luta decolonial implica reconhecer a necessidade de construção de outras condições de conhecimento. Nesse sentido, o questionamento e a abertura à necessária transgressão das bases epistemológicas universalistas sinalizam para um movimento propenso a desafios, visto que supõe o enfraquecimento de posições hegemonizadas em relação à produção de conhecimento e às suas pretensões de verdade(iro). É nessa perspectiva que se tecem as considerações sobre os desafios que se fazem sentir, no trabalho de professoras/es, na inserção da História e da Cultura Afro-Brasileira, em suas práticas de sala de aula, como demandadas pela Lei. Já o fomento de pensamentos, práticas e experiências por parte de professoras/es que desafiam a "matriz colonial" (WALSH, 2010b) será tomado como potencialidades que se mostram diante da implementação dessa Lei, em um contexto de colonialidade germânica.

Como se trata de um mesmo movimento que se tece enredado por desafios e potencialidades, as análises das falas de professoras/es são feitas em torno desse movimento, de forma que se possa pensá-las quanto à potência que sugerem, seja em termos de tensionamento quando de seus olhares sobre a colonialidade germânica, seja em termos de proposições/construções em uma perspectiva multi/intercultural crítica, em se tratando de pensar os desafios e potencialidades que a Lei 10.639/2003 (BRASIL, 2003) sugere em termos de experiência decolonial em escolas de Educação Básica em Novo Hamburgo.

Ainda, a título de introdução, destaca-se que o artigo, resultado de uma pesquisa mais ampla, caracteriza-se pela originalidade, pois, durante o seu desenvolvimento, realizou-se um estado do conhecimento e percebeu-se que, no contexto investigado, ainda não foi efetuada uma investigação que privilegiasse a luta decolonial dos professores negros. Há várias lutas decoloniais investigadas em outros contextos brasileiros e elas estão inseridas ao longo do artigo (SISS E FERNANDES, 2014; SILVA, 2013; SANTOS; SILVA, 2017; PAULA, 2013; MAGALHÃES, 2010; LEITE, 2010; GOMES, 2011, 2017; COELHO E COLEHO, 2013). 
BACKES, Benício; BACKES, José Licínio. A luta decolonial de professores militantes da causa negra em contextos de colonialidade germânica.

\section{Sinalizações teórico-metodológicas}

A produção de dados foi feita mediante a prática de entrevista interativa (SILVEIRA, 2007), com pessoas negras - seis professoras ${ }^{2}$ e um professor - militantes da causa negra e comprometidas com a prática de inserção das questões étnico-raciais na Educação Básica, em escolas públicas da Rede Municipal de Novo Hamburgo. Recortes de suas falas, em diálogo com teóricos dos campos de estudos pós-coloniais, do grupo modernidade/colonialidade e de estudos étnico-raciais que se debruçam sobre a temática em questão, compõem a discussão sobre a luta decolonial em contextos de colonialidade germânica.

O contexto de colonialidade refere-se a uma invenção da modernidade, que procura justificar a construção de uma hierarquização racial/social, com base em supostas inferioridades raciais (o não-europeu) de um lado e de pretensas superioridades raciais (europeu), de outro. E, com base nessa hierarquização procura negar, destruir, primitivizar, inferiorizar e subordinar as diferenças. É um processo de negação, inferiorização, subordinação e dominação sobre grupos de pessoas (negros e indígenas, no Brasil) e suas respectivas culturas, religiões, espiritualidade, epistemologias, cosmologias e ontologias. E tudo isso sustentado por um pensamento colonial, produzido basicamente como processo de naturalização das diferenças, procurando legitimar práticas coloniais no âmbito da produção econômica e política e, também, nas perspectivas científica e teológica (QUIJANO, 2005; GROSFOGUEL, 2008; WALSH, 2010b; 2013).

Levando em conta essa colonialidade - em que a "matriz colonial, o sistema de classificação hierárquica racial civilizatória que tem operado e opera em distintas ordens da vida" (WALSH, 2010b, p. 221, tradução nossa) -, ao mencionar colonialidade germânica, referimo-nos aos processos de construção identitária sociocultural de populações de imigrantes alemães, vindos desde os inícios do séc. XIX à região do Vale dos Sinos/RS, e de seus descendentes, quanto às suas pretensões de se construírem como cultura hegemônica, procurando invisibilizar e inviabilizar a presença de outros grupos étnico-raciais, especialmente populações negras, através da produção de estigmas e discriminações em relação à diferença racial (MAGALHÃES, 2017). A região do Vale dos Sinos compreende os municípios de Araricá, Canoas, Campo Bom, Dois Irmãos, Estância Velha, Esteio, Ivoti, Nova Hartz, Nova Santa Rita, Novo Hamburgo, Portão,

\footnotetext{
${ }^{2}$ Uma das professoras, à época, ocupava cargo de gestão e será referida como gestora no decorrer das análises. Os nomes das/dos participantes da pesquisa foram trocados por pseudônimos sugeridos pelas/os mesmas/os.
} 
São Leopoldo, Sapiranga e Sapucaia do Sul (FEE, 2015), e situa-se junto à região metropolitana de Porto Alegre/RS.

Visto que os inícios da colonialidade germânica em Novo Hamburgo remontam à terceira década do século XIX, com a chegada de imigrantes europeus (povos germânicos) ao Vale dos Sinos, cabe problematizar essa colonialidade germânica, situando-a nos contextos da lógica da expansão do colonialismo europeu sobre o resto do mundo. Uma expansão europeia que se procura fortalecer mediante a elaboração/implantação da perspectiva eurocêntrica de conhecimento, alçando a invenção da ideia de raça à condição científica. Uma invenção a partir da qual os europeus intencionam justificar suas relações coloniais de dominação sobre os não europeus, forjando a naturalização de inferiorizações de povos subordinados/dominados, não somente quanto aos traços fenotípicos, como também quanto à sua cultura e mentalidades (QUIJANO, 2005), envolvendo suas concepções epistemológicas, cosmológicas, ontológicas e espirituais. A inferiorização de elementos que envolvem a cultura e a mentalidade do povo afro pode concretizar-se, atualmente, como ainda acontece em Novo Hamburgo, como prática de invisibilização desses elementos, a partir da invenção de uma cultura em particular, alçada à condição hegemônica. É um tipo de invenção que se fortalece através da estratégia de construção da branquidade como "presença ausente" (APPLE, 2001) e que se tece como lugar de referência única.

Já para pensar a multi/interculturalidade crítica, parte-se do conceito de multi/interculturalidade em sua dupla potência - percepção das "minúcias, sutilezas, artimanhas dos diferentes saberes/poderes que produzem as identidades em diferentes culturas" e como “aliança estratégica" (BACKES, 2013, p. 61) - associoando-a à interculturalidade crítica. Com Walsh (2010a; 2013) e Candau (2012; 2014a), entende-se que a interculturalidade crítica se trata de uma perspectiva de diálogo intercultural, em que o questionamento e a subversão das relações políticas (relações de poder) se articulam com as relações epistemológicas (de saber) e as relações ontológicas (de ser).

\section{Colonialidade e raça: memórias e experiências de tensionamento decolonial}

Saber que os inícios da invenção da "ideia de raça, em seu sentido moderno, não têm história conhecida antes da América" (QUIJANO, 2005, p. 107) e compreender os cenários dessa 
BACKES, Benício; BACKES, José Licínio. A luta decolonial de professores militantes da causa negra em contextos de colonialidade germânica.

invenção como suposto marcador biológico diferencial e, como tal, possibilidade de construção de uma hierarquização naturalizada de povos segundo diferenças étnico-culturais, mostram-se como duas condições a partir das quais se torna possível pensar algumas das relações de poder colonial. Relações que marcam tanto os processos de inferiorização e de subordinação, pretendidos por parte de quem se encontrava/julgava na posição de colonizador, como os processos de resistência, de concepção de estratégias e de criação de espaços de produção e afirmação cultural, social e religiosa (MAGALHÃES, 2017) e de lutas contra subordinações e inferiorizações culturais e raciais, empreendidas pelas populações negras, em terras americanas, brasileiras e novohamburguenses.

A compreensão dessas condições mostra-se decisiva para o tensionamento da colonialidade - engendramento de uma estrutura social, cultural e política fortemente hierarquizada, com base em questões de raça. Ao adentrar na colonialidade quanto ao que a constitui como projeto, encontra-se na invenção da ideia de raça "o principal elemento constitutivo, fundacional, das relações de dominação que a conquista exigia" (QUIJANO, 2005, p. 107).

O engendramento de relações sociais de subordinação e inferiorização a partir dessa configuração de poder, ao mesmo tempo em que reconhece, na América, novas identidades sociais como índios, negros e mestiços, ao colocá-las em relação com identidades sociais já constituídas geopoliticamente, como portugueses, espanhóis e europeus, procura redefini-las, conferindo-lhes também uma conotação racial. Essas identidades engendradas em relações de dominação passam a dar o tom aos lugares e papeis de cada uma das formações identitárias em uma sociedade que passa a justificar a hierarquização social com base em supostas inferioridades raciais de uns em relação a pretensas superioridades raciais de outros. Em outras palavras, transformam-se diferenças étnico-culturais em condições que permitem justificar a desigualdade social como derivada de condições de natureza - uma das marcas da colonialidade/modernidade.

Diferentes processos de naturalização passam a ser engendrados. Importa sinalizar que, embora a naturalização dos processos de subordinação e inferiorização recorrentes nas representações da diferença racial tenham se desenvolvido como "uma tentativa de deter o inevitável 'deslizar' do significado para assegurar o 'fechamento' discursivo ou ideológico" (HALL, 2016, p. 171), os significados - uma produção cultural - trazem consigo os contextos em que foram gestados e, dessa forma, pretendê-los únicos, fixos, inalteráveis torna-se uma 
BACKES, Benício; BACKES, José Licínio. A luta decolonial de professores militantes da causa negra em contextos de colonialidade germânica.

empreitada impossível do ponto de vista dos processos culturais. Daí as tentativas de constante reiteração da naturalização das diferenças raciais, quando das pretensões de fixá-las e transformálas em fonte de desigualdade social. Veja-se, nesse sentido, uma fala da professora Flor em relação ao questionamento que lhe fora feito sobre manifestações de preconceito e de racismo na escola, quando referia que esses ainda eram muito fortes nesse espaço:

O preconceito, principalmente em relação à cor da pele, porque sempre o negro é visto como uma coisa ruim. Tudo o que acontece de ruim é o negro, o negro é ladrão, o negro é isso, o negro é aquilo. E ainda tem muito a questão do cabelo, que nós temos o cabelo diferente [...]. Muitas vezes, se sofre por causa disso, colocam apelidos ou ficam fazendo piadinhas: - 'Ah, cabelo de bombril'! [...] [E em relação à religião?] Muito! Principalmente porque aqui nessa região [...] muitos alemães têm origem evangélica e sempre houve essa coisa de se pensar que as religiões afro estão ligadas ao mal. (Prof. ${ }^{a}$ Flor)

$\mathrm{Na}$ fala da professora Flor, há uma espécie de atualização dos diferentes esforços que vinham sendo feitos no período colonial, desde os religiosos, sob a liderança do cristianismo, até os pretensamente científicos, esmerando-se em reiterar a natureza das diferenças raciais (com destaque para o negro como fonte do mal) como forma de auferir legitimidade ao modelo de acumulação capitalista e ao processo civilizatório em constituição, em escala mundial. Nesse mesmo patamar, há as três práticas disciplinares pensadas por Beatriz Gonzáles Stephan - "as constituições, os manuais de urbanidade e as gramáticas do idioma" -, instituintes da cidadania latinoamericana do século XIX, abordadas por Castro-Gómez (2005, p. 81) e que se constituem como "dispositivos de saber/poder que servem de ponto de partida para a construção [da] invenção do outro" (CASTRO-GÓMEZ, 2005, p. 81).

O domínio da palavra escrita torna-se central nesse processo: a construção das leis, dos planejamentos, dos manuais, como os de urbanidade, e os tratados, como os de higiene, e o acesso a eles passa por esse domínio de compreensão da palavra escrita. O Estado, através do Direito, forja uma cidadania - subjetividade que lhe garante a governamentalidade. A Escola, através da Pedagogia, terá o cuidado de formar esse perfil de sujeito requerido pela modernidade: "homem, branco, pai de família, católico, proprietário, letrado e heterossexual" (CASTROGÓMEZ, 2005, p. 81), tornando os sujeitos produtivos e úteis à pátria. Destaca-se, nesse sentido, uma fala da professora Lyntia, ao rememorar algumas práticas de pesquisa desenvolvidas como estudante de Pedagogia, das quais se serve em suas aulas para trabalhar as questões étnico-raciais com seus alunos de $5^{\circ}$ ano. Uma fala que aponta para as restrições do acesso ao domínio da 
BACKES, Benício; BACKES, José Licínio. A luta decolonial de professores militantes da causa negra em contextos de colonialidade germânica.

palavra escrita e das restrições ao acesso às escolas para as populações negras - uma prática do século XIX que atravessa o século XX:

[...] eu fiz uma pesquisa sobre o papel da mulher negra na sociedade hamburguense e a gente viu que Novo Hamburgo tinha só uma escola de mulheres nas décadas de 1920-40 [...]. As mulheres só poderiam frequentar essa escola se fosse para fazer economia doméstica. Só tinha uma negra nessa escola e ela foi levada por uma senhora que na verdade queria que sua empregada aprendesse as coisas que ela fazia. [...] Essa foi então a trajetória de uma mulher negra, num curso de educação doméstica. Depois dali a gente vai ver mulheres negras na educação em Novo Hamburgo, só na década de 1970 quando começam os cursos de MOBRAL. (Prof. ${ }^{a}$ Lyntia)

Por mais que houve/há esforços reiterados por parte da colonialidade, empenhada na construção de um discurso hegemônico, passando pelos campos da moral, da religião e da ciência, como se pode depreender nas falas das professoras Flor e Lyntia, esses não se mostraram capazes de conter os efeitos da sua construção cultural. Uma construção cultural com história, isto é, como movimento/força que se tece nas/por relações de poder em conflito, associação, combinação e recombinação, situada em determinado tempo e espaço, logo, passível de ser descontruída em seus processos de criação cultural e, também, modificada e alterada por outras forças em disputa. Nas palavras de Hall (2016, p. 211):

[...] o significado começa a escorregar e deslizar. Começa a derrapar, ser arrancado ou redirecionado. Novos significados são enxertados nos antigos. Palavras e imagens carregam conotações não totalmente controladas por ninguém, e [...] significados marginais ou submersos vêm à tona e permitem que diferentes significados sejam construídos, coisas diversas sejam mostradas e ditas.

Essa impossibilidade de fixar o significado em termos de representação (HALL, 2016), por mais que os esforços sejam conjugados (articulação entre religião, ciência e economia), como se verificou durante a modernidade colonial, quanto à invenção de imagens estereotipadas de negros, deve-se às resistências, às contraestratégias e à articulação de intervenções por parte das populações negras, tanto em relação às imagens degradantes (preguiça e primitivismo inatos) como em relação às imagens idealizadas e sentimentalizadas (bom escravo $^{3}$ negro cristão; escrava doméstica fiel e dedicada; e nativo feliz - artistas, menestréis, tocadores de banjo, malandros) (HALL, 2016).

As diferentes intervenções, criativamente construídas pelas populações negras, encharcadas por suas práticas, cosmologias e epistemologias, remetem a práticas decoloniais e,

\footnotetext{
${ }^{3}$ No contexto específico, o uso dos termos escravo e escrava (e não escravizado/a) deve-se por remeter à naturalização dos processos de escravização, empreendidos pela modernidade/colonialidade.
}

Quaestio, Sorocaba, SP, v. 21, n. 3, p. 965-989, set./dez. 2019. 
BACKES, Benício; BACKES, José Licínio. A luta decolonial de professores militantes da causa negra em contextos de colonialidade germânica.

portanto, sem se pretenderem universais, como propugnam as epistemologias euro-usa-centradas (WALSH, 2010b). Para o pensamento e prática decolonial, se ainda há um universal a ser construído - a descolonização -, esse é o como projeto. Pois em suas formas de luta, isto é, em suas instaurações como processo, a descolonização se mostra tão diversa quanto as diferentes perspectivas por parte de cada um dos povos/grupos/comunidades subalternizados. Daí a importância de se ficar atento ao potencial epistêmico dos espaços não completamente colonizados (GROSFOGUEL, 2008). É a partir desses espaços/margens que se podem favorecer trocas epistemológicas e práticas, avançando quanto às possibilidades de fortalecimento de lutas em comum de diferentes povos/grupos/comunidades, em se tratando de posicionamentos e objetivos sintonizados em torno de causas comuns (LACLAU, 2011; SANTOS, 2002).

Habitar esses espaços/margens numa perspectiva epistemológica é o que permite entender, como a colonialidade germânica, em Novo Hamburgo, como abordada na presente discussão, foi/é construída a partir de um lugar que se assume explicitamente normal, porque germânico/branco. Em uma fala da professora Violeta - quando fez uma pausa em torno da conversa sobre suas vivências/experiências como criança, adolescente e jovem negra em Passo Fundo (cidade em que nasceu e em que fez sua formação acadêmica), foi-lhe perguntado como se deu sua inserção em Novo Hamburgo -, encontra-se uma marca expressiva dessa colonialidade:

[...] na chegada em algum ambiente, aqui da cidade, diferenciado, lembro-me muito de ter ido em dois clubes aqui com uma amiga, com as colegas da Rede [professoras de escolas municipais] e as pessoas perguntarem duas a três vezes: - Mas de onde é? - E dirigida a mim e não às outras pessoas que estavam juntas e que também não eram sócias. (Prof. ${ }^{\text {a Violeta) }}$

É a colonialidade germânica, cristã e branca, que, ao inventar a diferença a partir da mesmidade, transforma-a em fonte do mal (SKLIAR, 2003) e procura constrangê-la, repetindolhe a mesma pergunta, que passa a assumir outros contornos como se estivesse a perguntar também: Mas como assim? Quem a convidou? Quem pensa que você é? O que veio fazer aqui? A pergunta: "Mas de onde é?", ao se desdobrar em várias outras, reaviva velhas identidades engendradas em relações de inferiorização e subordinação, que passam a dar o tom aos lugares e papeis de cada uma das formações identitárias, em uma sociedade hierarquizada social e racialmente. Magalhães (2010) em seus estudos sobre identidade negra em Novo Hamburgo, uma comunidade germânica, refere que "a coexistência entre aceitação e negação da presença dos negros azia-se presente no cotidiano da comunidade” (MAGALHÃES, 2010, p. 52). É uma 
BACKES, Benício; BACKES, José Licínio. A luta decolonial de professores militantes da causa negra em contextos de colonialidade germânica.

coexistência que, ainda hoje, não abre mão de algumas concessões que devem ser feitas por parte de quem é visto como diferente e pretende inserção maior na sociedade. É como se fosse uma espécie de permissão (e, dessa forma, remonta às cartas de alforria) que vem acompanhada da necessidade de um "plus" (como nos tempos de alforria) que faça jus à inserção pretendida, mesmo que em escalas que pareçam mais democráticas, como o é a inserção no mundo do trabalho, através de seleção por concurso público.

Nesse contexto de coexistência, mais especificamente quanto às concessões, encontra-se a fala do professor Bira, que vê, nesse tipo de prática cultural, uma prática de fechamento e uma especificidade da cultura alemã, em Novo Hamburgo. Falando sobre o mito da democracia racial no Brasil, foi perguntado ao professor Bira se havia preconceito na escola. Ele respondeu: "Entre quem? Entre alunos ou entre professores?" (Prof. Bira). Respondeu-se que tanto entre alunos como entre professores e entre professores e alunos. Ao que respondeu:

Na verdade, faz parte da cultura alemã: Pode entrar na minha comunidade, mas desde que tragas alguma contribuição. Tipo assim: - [Bira], tu vens lá de Canoas para trabalhar aqui, mas tu vais pegar teu dinheirinho aqui e vais aplicar em Canoas, por que tu não aplicas aqui? Se tu começares a aplicar aqui, tu és do nosso grupo. Então tem muito disso. Claro que ninguém fala, mas indiretamente a gente sabe que isso faz. parte da cultura alemã. (Prof. Bira)

A descrição do que "faz parte da cultura alemã", como referiu o professor Bira, fazendo uma crítica a esse tipo de prática de concessão que permite a entrada na comunidade - um possível retorno financeiro -, associa-se a uma prática de racismo velado, que se mostra na articulação entre raça/“estrangeiro”/classe. Trata-se de um racismo velado, que procura associar a diferença racial à desigualdade social como "resultado de problemas estruturais do país e não do preconceito, ou somente do seu passado escravista - como defendiam as teses dos autores da escola paulista desde a década de 1950” (SANTOS; SILVA, 2017, p. 440). Dessa forma, articular estratégias que permitam sua desconstrução passa, também, por esse tensionamento da colonialidade germânica/branca, que, por se entender como normalidade, ainda (im)põe condições à entrada de outros em sua comunidade/normalidade. E uma das estratégias de estilhaçá-la, quanto às suas pretensões de normalidade, consiste em expô-la, falar dela, fazê-la aparecer, como faz o professor Bira e como "denuncia” a professora Violeta.

Já nos contextos de um "plus", a coexistência entre aceitação e negação da presença negra se reatualiza quando de certas funções que passam a ser ocupadas por negros e negras. A docência é uma dessas funções que, ainda nos anos 90 do séc. XX, soava estranha em uma cidade 
BACKES, Benício; BACKES, José Licínio. A luta decolonial de professores militantes da causa negra em contextos de colonialidade germânica.

em que o imaginário da imigração germânica permanecia forte, tendendo ao enaltecimento de si própria, em detrimento de qualquer outra formação identitária, sobretudo a identidade negra.

Dessa forma, a docência negra, quando presente e referida, parece vir acompanhada de uma conjunção adversativa - "mas" - como a recordá-la de que, como negra, em uma sociedade marcada pela colonialidade, é preciso algo a mais (um "plus") - "um diferencial", como refere a professora Violeta - do que é necessário para um branco ser reconhecido profissionalmente nessa atividade. Isso se torna mais visível em uma das falas da professora Violeta que, ao ser perguntada sobre sua inserção na comunidade de Novo Hamburgo, falou que se deu pelo trabalho na rede pública municipal, através do seu diferencial de formação:

Naquele período, em 1987, eu era uma das poucas professoras negras que a Rede Municipal tinha e eu lembro, porque no espaço do nosso centro de cultura cabiam umas 500 professoras da Rede que eram daquela época. Então, a gente conseguia ver o que era o universo da Rede. [...]. Éramos meia dúzia, acho, de professoras negras, naquele período. [...] a inserção na rede pública municipal se deu de uma forma muito boa. Eu senti muito essa questão de uma valorização pela formação até porque naquele período eram pouquíssimos professores, na rede, que tinham graduação. O concurso público era só com o magistério, o curso normal e eu já era uma professora que tinha graduação. Tanto que na escola para a qual eu fui, num universo de 30 professoras, eu era a única graduada. No universo da Rede Municipal, nós éramos, acho 20 e poucas, trinta professoras graduadas. [...]. Então, já era um diferencial. (Prof. ${ }^{\text {a Violeta) }}$

O fato de a professora Violeta já ter em seu currículo a graduação, algo ainda pouco comum entre os docentes em Novo Hamburgo, nos anos de 1980, e sequer requerido para prestar o Concurso Público Municipal para docentes, é seu código de acesso, seu "diferencial” que lhe garante "uma forma muito boa" (Prof. a Violeta) de inserção nesse universo profissional, embora que essa não seja condição suficiente para a eliminação de práticas racistas. Quanto a esse aspecto da busca pela formação, convém referir a aposta/luta histórica que as lideranças negras e o Movimento Negro (man)tiveram na importância da educação/formação como perspectiva de maior inserção na sociedade. Destaca-se, nesse sentido, já nos anos de 1930, a fundação, em 16 de setembro de 1931, com sede em São Paulo, da Frente Negra Brasileira, que concentrava seus esforços na educação e no domínio da ciência, da literatura e das artes como forma de vencer o preconceito racial e garantir a inserção dos negros na sociedade vigente (MUNANGA; GOMES, 2006). Essa é, também, uma das marcas da luta do Movimento Negro brasileiro - a garantia do acesso igualitário à educação, que, a partir dos anos de 1990, pauta-se, também, pela luta por políticas de ação afirmativa (GOMES, 2011; 2017), que "têm como foco a população negra, mas não se restringem a ela. Visam à construção da sociedade e da educação como espaços/tempos mais igualitários, democráticos e justos para todos”(GOMES, 2017, p. 38). 
BACKES, Benício; BACKES, José Licínio. A luta decolonial de professores militantes da causa negra em contextos de colonialidade germânica.

Ainda quanto à coexistência entre aceitação e negação da presença negra, em outra perspectiva, embora nos mesmos contextos, tem-se o posicionamento da professora Ísis Angela, que sinaliza para a necessidade de um permanente tensionamento dessa coexistência. E, nesse sentido, aproxima-se da compreensão de Siss e Fernandes (2014, p. 113), que apontam a educação como "um espaço carregado de tensão e de conflito onde se trava uma luta cotidiana contra o racismo em todas as suas dimensões e as desigualdades sociorraciais". Quando falava sobre o estranhamento que ainda se verifica quanto à presença de religiões de matriz africana na escola, perguntou-se à professora Ísis Angela sobre como a Lei 10.639/2003 pode contribuir para ampliar as possibilidades de circulação da cultura afro na escola. Como resposta, traz à cena algumas das interrupções (HALL, 2013) que a cultura afro produz quando da sua entrada no espaço escolar:

[...] tentando todos os dias diminuir essa resistência [...] - O que tu queres fazendo aqui? - Quem essa negra pensa que é para fazer esse trabalho aqui, agora? Tu chegaste agora, chegaste ontem! Esse espaço é meu! Eu sempre estive aqui! E na verdade, não é para tirar espaço de ninguém, para que a gente possa dividir os espaços, que a gente possa disseminar conhecimento. (Prof. ${ }^{a}$ Ísis Angela)

Nesse posicionamento da professora Ísis Angela, a coexistência cede lugar à nãoaceitação da diferença que adentra um espaço ainda avesso a práticas e pessoas que o tensionem quanto ao que fora até então - um espaço de normalidade branca. E a pergunta "O que tu queres fazendo aqui? " (Prof. a Ísis Angela), em uma perspectiva de pensamento colonial, revela-se uma das facetas mais cruentas da colonialidade: a tentativa de manter, com base na fixação de lugares e identidades, a sociedade social e racialmente hierarquizada.

Colonizar, entre outras coisas, implica imposições, inferiorizações, negações. Implica a despersonalização do outro, conferindo-lhe uma identidade inferiorizada, estereotipada. Os estereótipos, geralmente forjados em sociedades produzidas por meio de modelos sociais e institucionais rigidamente hierarquizados, sinalizam para uma junção de ideias preconcebidas com expectativas/fantasias de desempenho e de ameaças, alimentadas por quem se posiciona social, cultural, política e, em sociedades racistas, racialmente superior em relação à construção de um "outro" inferiorizado. O estereótipo, na situação colonial, encontra sua validade na força da ambivalência (BHABHA, 2014). Uma ambivalência que:

[...] garante sua repetibilidade em conjunturas históricas e discursivas mutantes; embasa suas estratégias de individuação e marginalização; produz aquele efeito de verdade probabilística e predictabilidade que, para o estereótipo, deve sempre estar em excesso do que pode ser provado empiricamente ou explicado logicamente (BHABHA, 2014, p. 118).

Quaestio, Sorocaba, SP, v. 21, n. 3, p. 965-989, set./dez. 2019. 
BACKES, Benício; BACKES, José Licínio. A luta decolonial de professores militantes da causa negra em contextos de colonialidade germânica.

A ambivalência, nesses termos, pode ser entendida, talvez, como forças em estado agonístico - o outro é simultaneamente individuado e marginalizado e, também, simultaneamente, dele se constroem tanto efeitos de verdade possíveis como se atribuem efeitos de realidade ao dito: "ele é o dito". Dessa forma, a ambivalência se mostra como uma das condições de adentrar no discurso colonial, que "produz o colonizado como uma realidade social que é ao mesmo tempo um 'outro' e ainda assim inteiramente apreensível e visível” (BHABHA, 2014, p. 124).

Apreensível e visível, porque fixado em representações estereotipadas, compondo uma totalidade que se constitui em um jogo de poder. Um "outro", porque marcado por essa ambivalência, que se encontra na fala da professora Ísis Angela, a qual, ao ser perguntada sobre como as culturas negras entram na escola, relatou suas experiências de viver na cidade de Novo Hamburgo, como pessoa negra, a partir da segunda metade da primeira década do séc. XXI:

E me assustava muito. Andar pela cidade, circular no ônibus e as pessoas te olharem com estranhamento; quase uma comoção quando tu entras de turbante ou com as minhas roupas! Isso para mim é o meu cotidiano, mas assusta algumas pessoas ainda. Ir no centro e as crianças chorarem, porque nunca viram um negro na vida. E de tu não enxergares pessoas negras circulando pelos espaços comuns, no centro. (Prof. ${ }^{a}$ Ísis Angela)

Uma ambivalência em que as diferentes experiências de afirmação do ser negro tendem a ser vistas como estranhas na lógica da colonialidade germânica, porque segundo ela essas não têm razão de aparecerem, pois são entendidas como inferiores ou inexistentes. Daí a estranheza quando da sua visibilidade. Daí, também, a inconformidade por parte da colonialidade branca quando espaços de poder, tradicionalmente ocupados pela branquidade, passam a compor os cenários de possibilidades de ocupação por parte de pessoas negras.

A narrativa da professora Lyntia sobre suas experiências como diretora de uma escola de Educação Infantil também está associada às marcas da colonialidade germânica em Novo Hamburgo. Ao concluir sua fala sobre a pergunta anterior, que lhe fora feita quanto às dificuldades de se trabalhar a cultura afro em uma cidade, em que há um imaginário de predominância de uma cultura germânica, perguntou-se a ela sobre racismo na escola: Há racismo, hoje, na escola? Como se manifesta? Como a escola enfrenta, isso? A sua resposta é marcada pelos cenários de ambivalência de uma afirmação da negritude, situando-os como necessidade de "perceber o fio" (Prof. a Lyntia). Uma necessidade que remete a um dizer de Fanon (2008) quando das suas discussões em relação às possibilidades de compreensão das 
BACKES, Benício; BACKES, José Licínio. A luta decolonial de professores militantes da causa negra em contextos de colonialidade germânica.

relações de dependência, produzidas em uma situação colonial: "O problema da colonização comporta [...] não apenas a intersecção de condições objetivas e históricas, mas também a atitude do homem diante dessas condições” (FANON, 2008, p. 14). Pela fala da professora Lyntia, quem melhor pode compreender isso é quem vive(u) esse processo de forma objetiva. Assim, sobre o racismo presente nas escolas, ainda velado e não enfrentado, disse:

A escola não enfrenta. Porque ele é muito velado. É uma coisa que existe, que tu que és negro percebe, tu que és branco, jamais vais perceber, mas porque és negro, percebe. [Todo negro percebe?] Todo negro percebe. E não é que é da cabeça do negro! [...] Eu não consigo te explicar isso, porque é uma coisa que está ali, mas tu não pegas. Se tu pegasses, tu conseguirias perceber o fio, de onde surge, da onde vem, porque vem. Eu vou te contar uma história minha muito particular. [...] No final dos anos 90 para os inícios dos anos 2000, eu assumi o cargo de direção de uma EMEI aqui em Novo Hamburgo. [...] E lá pelas tantas, foi a semana de 20 de novembro, o [jornal] NH foi na minha escola e quis fazer uma reportagem. [...] Fui página central do NH. "Novo Hamburgo já tem diretora negra!" [...] A partir dai, gerou um caos no grupo de professoras que faziam parte da minha equipe de trabalho, naquela época. Elas me chamaram e disseram assim: "Olha aqui ó, ninguém vai se fazer em cima de nós, em cima de mim não! É porque fez aquela reportagem do NH, o trabalho é feito por nós!" Então me lançaram na cara: "Como é que é: tu estás te fazendo em cima de nós?" E eu era negra! O resto das professoras eram brancas. E a SMED o que fez? Começou a fazer reunião. "Vamos tirar os fantasmas dos corredores." Que fantasma era esse? (Prof. ${ }^{a}$ Lyntia).

"Perceber o fio", como ensina a professora Lyntia, olhando para as tramas que tecem sua experiência de professora negra, em um cargo de direção à frente de um grupo de professoras brancas, passa pelo embrenhar-se na teia heterárquica (GROSFOGUEL, 2008) que entrelaça diferentes fios, forjando nós intensamente fechados no sentido de impedir sua abertura/decifração quanto ao que os constitui em termos de condições objetivas e subjetivas. A abertura desses nós, como se percebe na própria narrativa da professora Lyntia, passa pela percepção do fio. É um fio que se tece no jogo das relações de poder em torno de afirmações identitárias marcadas pela colonialidade branca, forjando-se como normalidade mediante a negação, a anulação e a consequente invisibilização de tudo o que pode feri-la em sua pretensa normalidade. Nesses termos, "perceber o fio" passa por pensar nos desafios de outros lugares de enunciação capazes de tensionar a matriz colonial (WALSH, 2010b).

\section{Dos desafios de outros lugares de enunciação}

A potência do movimento feito por professoras/res, como questionamento às bases epistemológicas universalistas e como fomento de pensamentos, de práticas e experiências que desafiam a "matriz colonial" (WALSH, 2010b), mostra-se presente desde seus lugares de enunciação. Lugares marcados pela luta por afirmação de uma identidade, de uma história que, 
BACKES, Benício; BACKES, José Licínio. A luta decolonial de professores militantes da causa negra em contextos de colonialidade germânica.

embora negada pela história escrita, manteve-se viva pela tradição oral, como memória coletiva que se tece a cada recontar, a cada lembrança ressignificada e revivida nas trajetórias de existência das populações negras. Assim, em uma análise quanto aos desafios de se trabalhar com as questões da História e da Cultura Afro-Brasileira em uma comunidade de colonialidade germânica - quando perguntado à gestora Jurema se existe alguma implicância em se trabalhar essas questões nas escolas - tensiona esse lugar colonial hegemonizado e aponta para a perspectiva de um "entre-lugar" (BHABHA, 2014) como lugar de enunciação. Nas suas palavras:

[...] temos muitos professores que são de descendência germânica, alemã, eles ficam com receio de trabalhar sobre cultura-afro. Dizem o seguinte: "Por que só trabalhar cultura-afro?" Eu chegava e dizia para eles: "Só trabalhar a cultura-afro é porque foi um povo que foi esquecido, que não teve sua história contadaessa história vem sendo contada mais com tradição oral. Que os livros surgiram agora que falam sobre este povo, essa história". E ai os professores diziam: "Pensando por esse lado, é verdade!". (Gestora Jurema)

O que a gestora Jurema aponta mostra-se como um processo de negociação que se forja no encontro de culturas (BHABHA, 2014). Assim, o que se encontra em jogo é a compreensão de que existem diferentes lugares de enunciação, diferentes formas de contar a história, diferentes epistemologias, diferentes construções identitárias que se mantêm vivas em suas matrizes culturais. Nesses contextos, a menção “Pensando por esse lado, é verdade!” (Gestora Jurema), mais que a explicitação de uma concordância e de um reconhecimento quanto às diferenças presentes no encontro de culturas, por parte dos "muitos professores que são de descendência germânica, alemã " (Gestora Jurema), atenta para a relativização da verdade e de sua produção. Ou seja, o que se via como único - o conhecimento e a verdade, contidos nos livros - passa a se revestir de contextualidade e, assim, torna-se tão somente mais uma forma de conhecimento e mais uma verdade, abrindo-se para horizontes de pluralidade. Isto é, outras epistemologias, outras histórias, outras culturas, outras experiências de viver, outros lugares de enunciação, outras verdades são visibilizadas.

A expressão "sentir essa cultura", utilizada pela professora Rosa, quando questionada sobre a formação docente em relação à Lei, promovida pela Secretaria Municipal de Educação, marca esse lugar de produção de visibilidade, que é, também, um lugar de disputa, marcado por relações de poder. Nas suas palavras:

Era um curso muito rico em termos de cultura, em termos de Lei. Só que faltou empenho do município também de que esses professores pudessem realmente participar nas práticas. [...] que o professor pudesse realmente sentir essa cultura. [...]. Acho muito forte isso [imaginário da cultura alemã]. É bem forte mesmo. Não que se desvaloriza, mas intrinsecamente não se dá exatamente o grande valor que deveria ser. Todo o município fazia o curso e em nenhum momento você viu isso em nada, em nenhuma mídia. (Prof. ${ }^{a}$ Rosa)

Quaestio, Sorocaba, SP, v. 21, n. 3, p. 965-989, set./dez. 2019. 
BACKES, Benício; BACKES, José Licínio. A luta decolonial de professores militantes da causa negra em contextos de colonialidade germânica.

A Prof. ${ }^{a}$ Rosa, ao falar que o professor precisa "sentir essa cultura”, fez uma expressão corporal que lembra um abraço, aproximando-se de uma compreensão de que, nos encontros culturais, as identificações são forjadas pelos significados que se encontram em jogo nas relações de poder, presentes nos discursos de representação, produzidos pela cultura. Assim, "sentir essa cultura”, como enfatizou a professora Rosa, é a possibilidade ambivalente de ser acariciado, abraçado e confrontado por outras lógicas culturais, fundamentadas em outras epistemologias, outras cosmologias e outras ontologias. É poder mergulhar em outro cenário e se permitir a interpelação com a diferença. É, ainda, deixar-se possuir/constituir por uma diferença que obriga ao questionamento/tensionamento de representações que já não dão conta da experiência vivida. Questionamento/tensionamento que se produz como abertura ao diálogo com a diferença, como abertura para a produção de outras representações, em diálogo com outros discursos de produção de saber/poder.

Ao estabelecer uma relação entre as diferentes potencialidades que o "sentir essa cultura" (Prof. ${ }^{a}$ Rosa) traz e algumas marcas da colonialidade germânica em Novo Hamburgo - uma colonialidade cristã e branca -, é possível entender a profundidade da crítica da professora Rosa em relação ao processo de formação docente para a inserção da História e da Cultura AfroBrasileira nas escolas. O que a professora Rosa teceu como crítica a uma dupla ausência - não poder "sentir essa cultura" e maior visibilidade ao evento - constitui-se em uma crítica ao pensamento colonial, que inventa a diferença a partir da mesmidade (SKLIAR, 2003): invenção do outro a partir de si, que não é o outro. É o outro inferiorizado, subalternizado e que, em uma lógica de tolerância tecnocrática, "marca, de uma vez e para sempre, a distância entre o 'eu' e o 'outro', a macabra distância entre o ‘nós' e o ‘eles'” (SKLIAR, 2004, p. 83).

O que se encontra em jogo na lógica de tolerância tecnocrática não tensiona as formas de invenção de um outro e sequer implica possibilidades de pensar o "outro em relação a nós mesmos" (SKLIAR, 2004, p. 82), a não ser como alguém a ser tolerado. Assim, a tolerância tecnocrática não passa de uma estratégia de reafirmação do outro inventado pela mesmidade. Essa é a potência compreensiva que deriva do dizer da professora Rosa: "Não que se desvaloriza, mas intrinsecamente não se dá exatamente o grande valor que deveria ser”. Ou seja, na perspectiva da mesmidade, em que o outro é inventado pelo mesmo, esse sempre será algo menor a ser tolerado em um universo em que o mesmo é equivalente ao normal, verdadeiro e universal, três das grandes invenções do pensamento colonial. 
BACKES, Benício; BACKES, José Licínio. A luta decolonial de professores militantes da causa negra em contextos de colonialidade germânica.

Reconhecer que há críticas à tolerância não significa defender a intolerância. O desafio está em mudar o discurso sobre a intolerância, implodindo-a em seus sentidos anteriores. Isso significa que já não se pode usá-la mais para "diferir a morte do outro” (SKLIAR, 2004, p. 83) seu primeiro sentido -, nem para referir "uma virtude própria do eu e/ou do nós" (SKLIAR, 2004, p. 83) - segundo sentido. Em uma acepção à fala da professora Rosa, isso passa pela possibilidade de conferir valor ao outro, procurando minar a “separação do 'eu' e do 'outro', na medida em que tudo é diferença, tudo é alteridade: alteridade em mim e alteridade no outro" (SKLIAR, 2004, p. 83).

Daí a importância de "sentir essa cultura" (Prof.a Rosa). É um sentir que, também, contribui para o engajamento da docência em torno de processos educativos voltados à afirmação da identidade negra - uma reivindicação histórica do Movimento Negro (GOMES, 2011), transformada em desafio que justifica a necessidade da implementação da Lei 10.639/2003, concebendo a professora e o professor como elos desse tipo de educação (LEITE, 2010). Quanto a essa perspectiva do engajamento fomentado pelo "sentir essa cultura" (cultura afro), destaca-se a fala da professora Violeta, ao avaliar a possibilidade de docentes se tornarem multiplicadores de conhecimentos construídos em seus processos de formação continuada:

Qual foi a ideia da Secretaria daquele período? De que esses professores que fizessem os cursos atuassem como multiplicadores [...], mas a gente vê que realmente essa ideia do multiplicador não vinga muito. Acaba sendo realmente aquelas pessoas que se interessam pela causa, professores mais engajados, seja pela sua própria origem étnico-racial, seja por participarem de movimento social, seja por serem pesquisadores ou pela comunidade, enfim, por vários motivos, engajados culturalmente, socialmente. (Prof. 'Violeta)

É um "sentir essa cultura" que passa pelo engajamento com a causa negra que, de acordo com a professora Violeta, pode-se desdobrar em diferentes âmbitos: social, cultural, étnico-racial, acadêmico, político, comunitário. Engajamento que passa pelo "sentir essa cultura" e que produz identificações. Essas, em se tratando de diferentes âmbitos, a partir dos quais os sujeitos se posicionam e se pronunciam, podem assumir diferentes contornos. Há um somar-se à luta e que, em uma acepção a Laclau (2011, p. 93), pode ser pensada como uma "demanda equivalencial", que em dado momento (o momento da luta pela inserção efetiva da Lei na Educação Básica) resulta da produção de uma "articulação transitória" de diferentes sujeitos engajados e saberes comprometidos com uma luta, em que a diferença ocupa lugar central, tensionando identidades hegemonizadas. Essa é uma das possibilidades de se entender que é possível mesmo àqueles/as que não estão diretamente vinculados ao Movimento Negro, mas que de uma forma ou de outra 
BACKES, Benício; BACKES, José Licínio. A luta decolonial de professores militantes da causa negra em contextos de colonialidade germânica.

tensionam a produção da diferença encharcada pelas relações de saber/poder, somarem-se à luta por uma educação que implemente a Lei 10.639/2003. É nesses contextos que ganham relevância as questões discutidas a seguir e que sinalizam para o domínio do conteúdo e o desejo de trabalhá-lo, o comprometimento docente e a necessidade de um trabalho mais contínuo, quando das perspectivas de se pensar as potencialidades da Lei, em um contexto de colonialidade germânica.

\section{Das potencialidades de uma educação multi/intercultural crítica}

As perspectivas da multi/interculturalidade, em sua dupla potência, como argumenta Backes (2013) - possibilidades de perscrutar os processos de produção de identidades em diferentes culturas e possibilidades de tecer alianças estratégicas -, oferecem-se como duas condições com as quais se pode pensar potencialidades de uma educação multi/intercultural crítica a partir da inserção da temática étnico-racial, em escolas da Educação Básica, em contextos de colonialidade germânica. O domínio do assunto e o desejo de trabalhá-lo, apontados pela professora Flor como desafios à prática docente - quando provocada a falar sobre como percebe o trabalho com as questões de cultura afro - podem ser associados, respectivamente, com a dupla potência da multi/interculturalidade crítica. O domínio do assunto (Prof. ${ }^{a}$ Flor) permitirá perscrutar diferentes processos de construção de identidades e compreendê-los quanto às relações de poder implicados e, o desejo de trabalhá-lo (Prof. ${ }^{\text {a }}$ Flor), oferece condições de aproximação/interlocução com outras diferenças. Em suas palavras:

[...] para eu chegar numa sala de aula e falar sobre o assunto, eu tenho que ter domínio sobre ele. [...] Acho que um dos maiores desafios é que realmente os professores queiram que essa causa seja trabalhada em sala de aula e busquem um pouco mais de conhecimento sobre o assunto. Não é uma tarefa fácil, eu também estou sempre lendo, sempre buscando [...]. (Prof. ${ }^{\text {a Flor) }}$

O desejo de trabalhar as questões da História e da Cultura Afro-Brasileira, aliado ao comprometimento com essa causa, apropriando-se dos conhecimentos/saberes construídos pelo Movimento Negro em torno da causa negra (GOMES, 2017) é o que potencializa pesquisas/atividades que favorecem à criança “se sentir desse país em que ela vive", expressão utilizada pela professora Flor para referir-se à pertinência de se trabalhar, na escola, questões de História e Cultura Afro-Brasileira que envolvem a participação social, política, econômica e 
BACKES, Benício; BACKES, José Licínio. A luta decolonial de professores militantes da causa negra em contextos de colonialidade germânica.

cultural das populações negras na construção do Brasil e as suas lutas de resistência à escravidão, ao preconceito e ao racismo.

A criança poder "se sentir desse país em que ela vive" (Prof. a Flor) é, possivelmente, a tradução mais próxima do que se pode conquistar a partir de uma educação multi/intercultural crítica: o empoderamento de crianças e adolescentes educandas/os, a partir da apropriação de conhecimentos que lhes permitam compreenderem a si mesmas/os e à sociedade brasileira em suas diferenças culturais e lutas de afirmação identitária. E, nesse sentido, aponta para a potência de pensar a prática pedagógica, demandada pelo teor da Lei 10.639/2003, na perspectiva de uma prática intercultural crítica e interepistêmica, como ressaltam Candau (2012; 2014a) e Walsh (2010b).

Fomentar práticas interculturais críticas e interepistêmicas é, também, construir possibilidades de tensionar uma das dificuldades muito presente na colonialidade germânica -, manifestada nas falas de todos/as os/as participantes da pesquisa: a não-aceitação de certos temas, com destaque para a religiosidade de matriz africana. Religiosidade que faz parte da vida como um todo e que se mostra de difícil compreensão por uma lógica disciplinar, uma das marcas da epistemologia ocidental, em que as diferentes dimensões/manifestações do humano (epistemologia, cultura, história, cosmologia, política, economia) parecem manter uma relação de independência entre si, negando sua ambivalência (BAUMAN, 1999). Daí a expressão "choques de religiosidade", como referiu o professor Bira, mencionando algumas das dificuldades para as culturas negras entrarem na escola. Foi-lhe perguntado se entram na escola e como entram, ao que respondeu:

[...] a resistência e o preconceito ainda são muito grandes. [...] A gente consegue falar de quase tudo, mas quando chega na religiosidade, o professor fica constrangido, por quê? Porque não sabe como esse assunto vai ser levado para a casa pelos alunos. Então, muitas vezes, acontecem esses choques de religiosidade. (Prof. Bira)

“Choques", expressão utilizada pelo professor Bira, é um dos desdobramentos possíveis, produzidos a partir de um encontro cultural. Encontros culturais produzem tensões. As tensões envolvem potência, força. Força que, inclusive, se mostra como tal, mesmo quando voltada a manter algo como está - uma força/potência contrária à mudança. E é a esse tipo de choque que o professor Bira fez referência. Choque como força conservadora e reativa, que procura paralisar as possibilidades de mudança que podem derivar de negociações em encontros culturais. 
BACKES, Benício; BACKES, José Licínio. A luta decolonial de professores militantes da causa negra em contextos de colonialidade germânica.

Contudo, há, também, os choques que irrompem como tensão, produzindo fissuras, infiltrações, rupturas, fusões, (re)combinações que levam a transformações. A professora Flor, quando questionada sobre possíveis mudanças quanto às crianças e aos adolescentes a partir da inserção da História e da Cultura Afro-Brasileira, falou entusiasmada, de algumas situações que ela vivencia a partir do seu trabalho como professora de dança:

A gente percebe que muitas vezes eles começam a se dar conta de algumas atitudes que eles tinham anteriormente e que acabavam sendo atitudes preconceituosas e que, já tendo conhecimento a respeito daquele fato, começam a agir de uma maneira diferente. As alunas que estão comigo na dança perguntam: "Mas a gente vai aprender samba?" Claro! O samba também faz parte da Cultura Afro-Brasileira. Então, aprendendo a questão do samba, as danças afro em si, que são movimentos que estão relacionados a muitas questões da natureza, porque a questão dos africanos com a natureza é muito forte, tanto que as entidades, os orixás, estão sempre relacionados à alguma coisa com a natureza. Então, os gestuais que elas fazem, os movimentos, tudo isso elas aprendem. (Prof. ${ }^{a}$ Flor)

O relato da professora Flor, em uma perspectiva do trabalho com os educandos, vem ao encontro do "sentir essa cultura", que a professora Rosa trouxe em relação aos processos de formação continuada de docentes, como já discutido no item anterior. É um "sentir essa cultura" possível, porque o conhecimento sobre questões afro pode ser experienciado pelos educandos como prática social, cultural, corporal, rítmica, dançante, epistêmica e ôntica. É uma aprendizagem que se experiencia como corpo e espírito integrados, produzindo outros olhares em relação a si mesmo como sujeito que se produz e é produzido em uma cultura que se encontra em interação com outras culturas, outras epistemologias, outras cosmologias e ontologias, outros olhares em relação ao mundo, quanto à sua organização social, política e econômica, e em relação aos outros, quanto à produção das diferenças culturais e que, em uma sociedade hierarquizada social e racialmente (QUIJANO, 2005; GROSFOGUEL, 2008), tendem a ser transformadas em desigualdade.

A aprendizagem que deriva da experiência do encontro de culturas (BHABHA, 2014) e que adentra, a partir da Lei 10.639/2003, os espaços escolares da Educação Básica, produz diferentes tensionamentos que passam a pautar algumas questões que até então não pareciam entrar/estar em disputa. Assim, embora já se tenha conquistado, em diferentes frentes, espaços de participação e de reconhecimento, garantindo maior visibilidade à negritude, torna-se importante manter as apostas em atividades mais continuadas de inserção da História e da Cultura AfroBrasileira nas escolas, seu estudo e aprofundamento, que permitam o reconhecimento da participação negra na construção social, política, econômica e cultural da cidade. Ao mesmo 
BACKES, Benício; BACKES, José Licínio. A luta decolonial de professores militantes da causa negra em contextos de colonialidade germânica.

tempo, possibilidades de desconstrução de estereótipos e inferiorizações produzidos por sociedades social e racialmente hierarquizadas. É o que a professora Violeta, diante da pergunta sobre como as culturas negras entram na escola, que espaço elas têm hoje e como vão entrando ou se infiltrando, nomeia como necessidade de "chegar a um outro patamar" (Prof. a Violeta).

"Um outro patamar" que, visualizado em suas potencialidades de compreensão e informação sobre a "história do negro e dos afrodescendentes no nosso país" (Prof. a Violeta); de desconstrução do "estereótipo do negro ainda pautado do negro escravo", de problematização e desconstrução da branquidade, percebem-se próximas do que Candau (2014b) chama de educação intercultural crítica. Ou seja, nesse "outro patamar" (Prof. a Violeta) encontram-se em jogo as possibilidades de ir além de um olhar que situa as questões étnico-culturais apenas no campo das relações humanas, em uma perspectiva de criação de mecanismos de respeito, que garantam a convivência solidária com as diferenças. Encontram-se, ainda, em jogo, as possibilidades de superação das perspectivas interculturais funcionais que tendem apenas a acomodar as diferenças, preferencialmente assimilando-as através de integrações subalternizadas à cultura hegemônica.

O “outro patamar” (Prof. a Violeta), em uma concepção de educação multi/intercultural crítica, supõe compreender os movimentos e processos de construção das culturas e identidades, mediante articulações e negociações, envolvendo desestabilizações, (re)combinações e hibridizações, com destaque para as relações de poder/saber presentes nesses processos de construção. Assim, o “outro patamar" (Prof. a Violeta) supõe a desconstrução de estereótipos e de imagens "congeladas" da história e da cultura afro, superando o patamar da redução da História e da Cultura Afro-Brasileira à escravidão negra (SILVA, 2013) e de abordagens de questões étnico-raciais com teor mais moralizante. A produção de rupturas com abordagens mais moralizantes sobre questões étnico-culturais e com representações de negros que remontam ao período colonial, pode ser potencializada a partir de uma maior aproximação com estudos acadêmicos (COELHO; COELHO, 2013) e, também, com outras pedagogias, como as das Africanidades e da Prática Pedagógica Griô (PAULA, 2013), fomentando a reinvenção, a recontagem, a reedição e a reescrita de sua(s) história(s). 
BACKES, Benício; BACKES, José Licínio. A luta decolonial de professores militantes da causa negra em contextos de colonialidade germânica.

\section{Considerações finais}

A pesquisa mostrou que os/as professores/as negros/as desenvolvem diferentes práticas pedagógicas que, construídas numa perspectiva multi/intercultural crítica e decolonial, colocam em xeque a colonialidade germânica.

As falas das seis professoras e do professor, participantes da pesquisa, carregam as marcas de um engajamento com a causa negra pautado por estratégias de sobrevivência, de resistência, de protagonismo, de inserção à sociedade local, de lutas contra a discriminação racial que se traduzem, por sua vez, em construção de estratégias e iniciativas decoloniais como possibilidades de se pensar/articular/construir outras lógicas de compreensão de mundo, de vida, de sociedade, de cidade.

Nesses termos, os espaços das escolas da Educação Básica, são vistos em sua potencialidade transformadora das condições de grupos historicamente subalternizados e inferiorizados. E a luta, nesses espaços, em torno de uma afirmação maior da negritude é uma luta em estado agonístico (BHABHA, 2014). Uma luta tecida como tensão, ao estilhaçar práticas monoculturais e, como potência, ao favorecer práticas pedagógicas multi/interculturais críticas.

Entretanto, apesar da potência dessas lutas e dessas práticas, a questão que fica para a reflexão é até quando essa luta será uma luta quase restrita aos/às professores/as negros/as? Quando essa luta se tornará uma luta de toda a sociedade, tornando-a mais plural? Quando a educação deixará de ser um espaço privilegiado da cultura branca?

\section{Referências}

APPLE, Michael W. Políticas de direita e branquidade: a presença ausente da raça nas reformas educacionais. Rev. Bras. Educ., Rio de Janeiro, n. 16, p. 61-67, abr. 2001.

BACKES, José L. Os conceitos de multiculturalismo/interculturalidade e Gênero e a ressignificação do currículo da educação básica. Quaestio - Revista de Estudos em Educação, Sorocaba, SP, v. 15, n. 1, p. 50-64, maio 2013. Disponivel em: http://periodicos.uniso.br/ojs/index.php/quaestio/article/view/1632. Acesso em: 16 mai. 2018.

BAUMAN, Zygmunt. Modernidade e ambivalência. Rio de Janeiro: Jorge Zahar Editor, 1999.

BHABHA, Homi K. O local da cultura. 2. ed. Belo Horizonte: UFMG, 2014.

BRASIL. Presidência da República. Casa Civil. Subchefia para Assuntos Jurídicos. Lei no 10.639, de 9 de janeiro de 2003. Altera a Lei no 9.394, de 20 de dezembro de 1996, que estabelece as diretrizes e bases da educação nacional, para incluir no currículo oficial da Rede de Ensino a obrigatoriedade da temática "História e Cultura Afro-Brasileira", e dá outras providências. Brasília: Senado Federal, 2003. Disponível em: http://www.planalto.gov.br/ccivil_03/leis/2003/L10.639.htm. Acesso em: 16 set. 2015. 
BACKES, Benício; BACKES, José Licínio. A luta decolonial de professores militantes da causa negra em contextos de colonialidade germânica.

CANDAU, Vera. F. Diferenças culturais, interculturalidade e educação em direitos humanos. Educação e Sociedade, Campinas, v. 33, n. 118, p. 235-250, mar. 2012.

CANDAU, Vera. F. Educação intercultural: entre afirmações e desafios. In: MOREIRA, Antônio F; CANDAU, Vera M. (orgs.). Currículos, disciplinas escolares e culturas. Petrópolis: Vozes, 2014b. p. 23-41.

CANDAU, Vera. F. Ser professor/a hoje: novos confrontos entre saberes, culturas e práticas. Educação, Porto Alegre, v. 37, n. 1, p. 33-41, jan./abr. 2014a.

CASTRO-GÓMEZ, Santiago. Ciências sociais, violência epistêmica e o problema da "invenção do outro". In: LANDER, Edgardo. (org.). A colonialidade do saber: eurocentrismo e ciências sociais: Perspectivas latino-americanas. Buenos Aires: Clacso, 2005. p. 80-87.

COELHO, Wilma de N. B.; COELHO, Mauro C. Os conteúdos étnico-raciais na educação brasileira: práticas em curso. Educ. rev., Curitiba, n. 47, p. 67-84, mar. 2013.

FANON, Frantz. Pele negra: máscaras brancas. Salvador: EDUFBA, 2008.

FEE. Fundação de Economia e Estatística. Governo do Estado do Rio Grande do Sul. Corede Vale do Rio dos Sinos, 2015. Disponível em: https://www.fee.rs.gov.br/perfilsocioeconomico/coredes/detalhe/?corede=Vale+do+Rio+dos+Sinos. Acesso em: 16 mai. 2018.

GOMES, Nilma L. Diversidade étnico-racial, inclusão e equidade na educação brasileira: desafios, políticas e práticas. RBPAE, v. 27, n. 1, p. 109-121, jan./abr. 2011.

GOMES, Nilma L. O movimento negro educador: saberes construídos nas lutas por emancipação. Petrópolis: Vozes, 2017.

GROSFOGUEL, Ramón. Para descolonizar os estudos de economia política e os estudos pós-coloniais: transmodernidade, pensamento de fronteira e colonialidade global. Revista Crítica de Ciências Sociais, Coimbra, Portugal, n. 80, p. 115-147, mar. 2008. Disponivel em: https://journals.openedition.org/rccs/697. Acesso em: 14 out. 2017.

HALL, Stuart. Cultura e representação. Rio de Janeiro: PUC-Rio: Apicuri, 2016.

HALL, Stuart. Da diáspora: identidades e mediações culturais. Belo Horizonte: UFMG, 2013.

LACLAU, Ernesto. Emancipação e diferença. Rio de Janeiro: EdUERJ, 2011.

LEITE, Vanderlei F. Diversidade cultural e racial: desdobramentos da Lei 10639/2003 nas práticas escolares do estado de São Paulo. São Paulo: PUC/SP, 2010.

MAGALHÃES, Magna L. Associativismo negro no Rio Grande do Sul. São Leopoldo: Trajetos Editorial, 2017.

MAGALHÃES, Magna Lima. Entre a preteza e a brancura brilha o Cruzeiro do Sul: associativismo e identidade negra em uma localidade teuto-brasileira. 2010. 219p. Tese (Doutorado em História) Ciências Humanas, Universidade do Vale do Rio dos Sinos - UNISINOS. São Leopoldo, 2010.

MUNANGA, Kabengele; GOMES, Nilma Lino. O negro no Brasil de Hoje. São Paulo: Global, 2006. (Coleção para entender).

PAULA, Benjamin X. de. A educação para as relações étnico-raciais e o estudo de História e Cultura da África e Afro-brasileira: formação, saberes e práticas educativas. Uberlândia: UFU/FACED; PPGED/UFU, 2013.

QUIJANO, Aníbal. Colonialidade do poder, eurocentrismo e América Latina. In: LANDER, Edgardo. (org.). A colonialidade do saber: eurocentrismo e ciências sociais: perspectivas latino-americanas.

Buenos Aires: Clacso, 2005. p. 107-130

Quaestio, Sorocaba, SP, v. 21, n. 3, p. 965-989, set./dez. 2019. 
BACKES, Benício; BACKES, José Licínio. A luta decolonial de professores militantes da causa negra em contextos de colonialidade germânica.

SANTOS, Boaventura de Sousa. Para uma sociologia das ausências e uma sociologia das emergências. Revista Crítica de Ciências Sociais, Coimbra, Portugal, n. 63, p. 237-280, 2002. Disponível em: http://rccs.revues.org/1285. Acesso em: 14 out. 2017.

SANTOS, Raquel Amorin dos; SILVA, Rosângela Maria de Nazaré Barbosa e. Racismo científico no Brasil pós-escravista. Revista Contemporânea de Educação, Rio de Janeiro, v. 12, n. 25, p. 438-454, set./dez. 2017.

SILVA, Rutinéia C. M. Escola e questão racial: a avaliação dos estudantes. Franca: Unesp, 2013.

SILVEIRA, Rosa M. H. A entrevista na pesquisa em educação: uma arena de significados. In: COSTA, Marisa V. Caminhos investigativos II: outros modos de fazer pesquisa em educação. 2. ed. Rio de Janeiro: Lamparina, 2007. p. 117-138.

SISS, Ahyas; FERNANDES, Otair. Formação de professores na perspectiva de uma educação culturalmente diversificada: breves considerações. Série-Estudos: Periódico do Programa de PósGraduação em Educação da UCDB, Campo Grande/MS, n. 37, p. 107-119, jan./jun. 2014.

SKLIAR, Carlos. A materialidade da morte e o eufemismo da tolerância: duas faces, dentre as milhões de faces, desse monstro (humano) chamado racismo. In: GALLO, Sílvio; SOUZA, Regina M. de. (orgs.). Educação do preconceito: ensaios sobre poder e resistência. Campinas: Alínea, 2004. p. 69-90.

SKLIAR, Carlos. Pedagogia (improvável) da diferença: e se o outro não estivesse aí? Rio de Janeiro: DP\&A, 2003.

SPINASSÉ, Karen Pupp. Os imigrantes alemães e seus descendentes no Brasil: a língua como fator identitário e inclusivo. Conexão Letras, Porto Alegre, v. 3, n. 3, p. 125-140, 2008.

WALSH, Catherine. Estúdios (inter)culturales en clave de-colonial. Tabula Rasa, Bogotá, n. 12, p. 209227, jan./jun. 2010b.

WALSH, Catherine. Interculturalidad crítica y educación intercultural. In: VIAÑA, Jorge; TAPIA, Luis; WALSH, Catherine. Construyendo Interculturalidad Crítica. III - CAB. La Paz/Bolivia: Instituto Internacional de Integración del Convenio Andrés Bello, 2010a. p. 75-96.

WALSH, Catherine. Interculturalidad y (de)colonilidad: perspectivas críticas y políticas. Visão Global, Joaçaba. v. 15, n. 1-2, p. 61-74, 2013.

Quaestio, Sorocaba, SP, v. 21, n. 3, p. 965-989, set./dez. 2019. 